\title{
Up-regulation of serotonin receptor $2 B$ mRNA and protein in the peri-infarcted area of aged rats and stroke patients
}

\author{
Ana-Maria Buga1,2,*, Ovidiu Ciobanu'2,6,*, George Mihai Bădescu7, Catalin Bogdan², \\ Ria Weston ${ }^{3}$, Mark Slevin ${ }^{3}$, Mario Di Napoli ${ }^{4,5}$ and Aurel Popa-Wagner ${ }^{1}$ \\ ${ }^{1}$ Department of Psychiatry and Psychotheraphy, University of Medicine Rostock, Rostock, Germany \\ ${ }^{2}$ Center of Clinical and Experimental Medicine, University of Medicine and Pharmacy Craiova, Craiova, Romania \\ ${ }^{3}$ Department of Healthcare Science, Manchester Metropolitan University, Manchester, UK \\ ${ }^{4}$ Neurological Service, San Camillo de' Lellis General Hospital, Rieti, Italy \\ ${ }^{5}$ Neurological Section, SMDN-Center for Cardiovascular Medicine and Cerebrovascular Disease Prevention, Sulmona, \\ L'Aquila, Italy \\ ${ }^{6}$ Vivantes Humboldt-Klinikum, Center for Affective Disorders, Berlin, Germany \\ ${ }^{7}$ Psychiatry Clinical Hospital, University of Medicine and Pharmacy of Craiova, Craiova, Romania \\ * These authors have contributed equally to this work
}

Correspondence to: Aurel Popa-Wagner, email: aurel.popa-wagner@med.uni-rostock.de

Keywords: aging; stroke; post-stroke depression; serotonin receptor type B; neurogenesis; Gerotarget

Received: February 04, 2016 Accepted: March 14, $2016 \quad$ Published: March 22, 2016

\section{ABSTRACT}

Despite the fact that a high proportion of elderly stroke patients develop mood disorders, the mechanisms underlying late-onset neuropsychiatric and neurocognitive symptoms have so far received little attention in the field of neurobiology. In rodents, aged animals display depressive symptoms following stroke, whereas young animals recover fairly well. This finding has prompted us to investigate the expression of serotonin receptors $2 \mathrm{~A}$ and $2 \mathrm{~B}$, which are directly linked to depression, in the brains of aged and young rats following stroke. Although the development of the infarct was more rapid in aged rats in the first 3 days after stroke, by day 14 the cortical infarcts were similar in size in both age groups i.e. $45 \%$ of total cortical volume in young rats and $55.7 \%$ in aged rats. We also found that the expression of serotonin receptor type B mRNA was markedly increased in the perilesional area of aged rats as compared to the younger counterparts. Furthermore, histologically, HTR2B protein expression in degenerating neurons was closely associated with activated microglia both in aged rats and human subjects. Treatment with fluoxetine attenuated the expression of Htr2B mRNA, stimulated post-stroke neurogenesis in the subventricular zone and was associated with an improved anhedonic behavior and an increased activity in the forced swim test in aged animals. We hypothesize that HTR2B expression in the infarcted territory may render degenerating neurons susceptible to attack by activated microglia and thus aggravate the consequences of stroke.

\section{INTRODUCTION}

Stroke is the second-leading global cause of death behind heart disease, accounting for $11.13 \%$ of total deaths worldwide in 2015 [1]. Studies of stroke have demonstrated age and gender effects on incidence, functional recovery and mortality, not only in humans but also in animal models [2-4]. Therefore, studies on physiologically complex organisms including rats, mice and non-human primates are required to investigate the molecular mechanisms of aging in humans, to predict human responses to age-related diseases and also the response of aged organisms to therapeutic interventions. Since epidemiological studies have revealed that human stroke occurs more often in old ages (more than 80 years) than late middle age (60-79 years) [1], it is advisable to use rats of appropriate age to study the behavioral and molecular mechanisms underlying functional recovery 
after stroke in animal model. Therefore, the aged rodent model offers a useful tool to investigate the molecular pathways and potential novel therapies that may improve functional outcome after cerebral ischemia in preclinical studies [5].

Post-stroke depression (PSD) is among the most frequent neuropsychiatric consequences of stroke. Depression also negatively influences stroke outcome with increased morbidity, mortality and poorer functional recovery $[6,7]$. Morphologically, depression is associated with atrophy and loss of neurons and glia, which contribute to decreased size and function of limbic brain regions that control mood and depression, including the prefrontal cortex and hippocampus [8].

In addition to an increased risk of mortality, depressed patients are more likely to develop coronary artery disease, type 2 diabetes and cognitive deficits [9-12]. Depression also complicates the prognosis of other chronic diseases [13, 14]. However, the biological mechanisms underlying depression remains poorly understood due to a lack of biomarkers, relatively low rates of heritability, and heterogeneity of precipitating factors, including stress [15-17]. For example, a recent study has linked HTR2b polymorphisms to susceptibility to migraine/hypoperfusion without aura in a Spanish population [18].

In the normal adult brain, 5-HT receptor mRNA is present at high concentrations in the frontal cortex, basal ganglia and at lower levels in some components of the limbic system (including hippocampus, septum and amygdala) [19], while the highest expression of 5-HT2C receptor is found in the choroid plexus, with lower but substantial densities in other regions, lateral septal nucleus, subthalamic nucleus, amygdala and parts of the hippocampus, substantia nigra, central gray and cerebellum [20]. However, 5-HT2C did not show an agedependency in post-stroke rats and was, therefore, not investigate din this study. 5-HT2B receptor mRNA is mainly found in the hippocampus as well as the cortex, midbrain and the hypothalamus [21].

At the genetic and cellular level, we previously found significant differences in behavioral, cytological and genomic responses to injury in aged animals compared to younger controls [22-25]. Behaviorally, aged animals display depressive symptoms following stroke, whereas young animals recover fairly well [26]. This finding has been confirmed repeatedly in subsequent studies [25, 27], prompting us to investigate the expression of serotonin receptors $2 \mathrm{~A}$ and $2 \mathrm{~B}$, which are directly linked to depression, in the brains of aged and young rats following stroke.

\section{RESULTS}

To facilitate feeding in aged animals during the first three days post-stroke, we fed them with moistened, soft pellets. Nevertheless, aged animals do lose some weight in the first week following stroke. The mortality rate was higher for aged rats (33\%) than for younger rats $(15 \%)$ during this time.As previously reported, the hematologic parameters showed some age-associated differences, notably in blood pressure, but the differences were not statistically significant in this stroke model $[22,32]$.

\section{Hedonic behavior}

Before surgery, $79 \%$ of young animals and $75 \%$ of old animals were hedonic (Figure 1B). After stroke, the number of hedonic young animals did not change significantly over the 28 days testing period. However, in the old group the number of anhedonic animals has increased to $42 \%$ by day 21 and to $57 \%$ by day 28 (Figure 1B). The fluoxetine treatment however has reduced anhedonic behaviour to $35 \%$ by day 28 (Figure 1B, dashed line).

\section{Forced swim}

The forced swim test (FST) is commonly used for assessing antidepressant-like behavior in animal models. There are three predominant behaviors in the modified FST: immobility, swimming and climbing. The effects of lesion (stroke) and anti-depressant treatment with fluoxetine are shown in Figure 2. Stroke produced a decrease in cumulative activity (i.e. composed of swimming, climbing and immobility times) that decreased steadily from day 1 to day 28 (Figure 2A). Fluoxetine treatment, however, reversed partially the cumulative activity (Figure 2A, red line). When analyzed by activity type, swimming itself had a modest contribution to the total activity index. As expected, stroke led to an impairment of climbing activity that reached the lowest value at day 21 post-stroke. Likewise, immobility has increased steadily from pre-surgery levels to day 21 . The anti-depressant treatment led to an improvement in the swimming behavior mostly ( 5 -fold increase, $\mathrm{p}=0.001$ ) followed by an improvement in immobility (1.8-fold, $\mathrm{p}=$ 0.02) (Figure 2B).

\section{Age-specific post-stroke up-regulation of Htr2B mRNA in the peri-infarct area of rats}

Immunohistochemistry with NeuN, a marker of neuronal nuclei was used to reveal details of the infarcted area [27]. Although the development of the infarct was more rapid in aged rats in the first 3 days after stroke [31] by day 14 the cortical infarcts were similar in size in both age groups i.e. $45 \%$ of total cortical volume in young rats and $55.7 \%$ in aged rats (Figure $3 \mathrm{~A}-3 \mathrm{C}$ ).

Of the genes possibly involved in post-stroke 
Table 1: Case demographics for stroke patients.

\begin{tabular}{|l|l|l|l|l|l|}
\hline Pacient & Age & Sex & $\begin{array}{l}\text { Survival } \\
\text { time }\end{array}$ & $\begin{array}{l}\text { Stroke } \\
\text { type }\end{array}$ & $\begin{array}{l}\text { Region } \\
\text { analyzed }\end{array}$ \\
\hline 1 & 78 & F & $6 \mathrm{~d}$ & IS/ICH & CA \\
\hline 2 & 51 & F & $36 \mathrm{hrs}$ & IS & CA \\
\hline 3 & 68 & M & $12 \mathrm{hrs}$ & IS & CA \\
\hline 4 & 67 & M & $40 \mathrm{hrs}$ & IS & CA \\
\hline 5 & 51 & F & $36 \mathrm{hrs}$ & IS & CA \\
\hline 6 & NA & M & $20 \mathrm{hrs}$ & IS & CA \\
\hline 7 & 66 & M & $30 \mathrm{hrs}$ & IS & CA \\
\hline 8 & 72 & M & $8 \mathrm{~d}$ & IS/SAH & CA \\
\hline 9 & 78 & M & $18 \mathrm{~d}$ & IS & CA \\
\hline 10 & 88 & F & $7 \mathrm{~d}$ & IS/SAH & CA \\
\hline 11 & 68 & M & $27 \mathrm{~d}$ & IS & CA \\
\hline
\end{tabular}

IS indicates ischemic stroke; ICH, intracerebral hemorrhage;

$\mathrm{SAH}$, subarachnoid hemorrhage; CA, cortical area

depression, we found by transcriptomics analysis using the Affymetrix platform, that the transcripts encoding the serotonin receptor $2 \mathrm{~B}$ (Htr2b) but not Htr2a were upregulated after stroke in the aged rat stroke model. The expression also displayed a strong age effect, being more strongly upregulated at day 3 in aged than in young rats. The Htr2b mRNA levels returned almost to the prestroke level by day 14 [25]. To validate these results, we performed RT-qPCR. At day 3 post-strokewe found by RTqPCR,a 15-fold up-regulation in the expression of Htr2b mRNA, that was 7-fold higher in the lesioned area of aged animalsthan in young animals (Figure 3D). Ht2b mRNA levels decreased thereafter in the perilesional area in both age groups. Fluoxetine treatment, however, caused, by day 28, a significant increase (1.9-fold) in the Htr2b mRNA levels in the perilesional area of aged rats (Figure 3D).

To determine the phenotype of Htr2B-positive cells, we performed double-immunofluorescence staining using a mouse antibody against HTR2B (green) and a rabbit antibody raised against $\mathrm{NeuN}$ (red). We found that HTR2B-positive cells were co-localized with NeuNpositive nuclei at day 3 after stroke in aged rat brains (Figure 3E, arrows). Although the mRNA expression was largely down-regulated by day 14 post-stroke, the HTR2B/NeuN protein co-localization persisted in the periinfarcted area (Figure 3F, arrows).

\section{HTR2B is expressed by neurons and astrocytes in the peri-infarcted area of human subjects}

By chemical immunostaining, the HTR2B receptor in human subjects has a perinuclear localization in the penumbral region of post-mortem stroke patients (Figure 4A, arrows). By immunofluorescence, a similar co-localization was observed in the peri-infarcted area between HTR2B-positive cells (green) and cells labeled by beta III tubulin (red), a marker of mature neuronal cells (Figure 4B, arrows). In addition to the neuronal co-localization, we also noted the co-localization with astrocytes labeled with FITC-GFAP (Figure 4C, arrows) in the penumbral region of post-mortem stroke patients. However, there was no co-localization with astrocytes in the unlesioned, contralateral region of the same poststroke patient (Figure 4D, arrowheads).

\section{HTR2B is surrounded by activated microglia in the peri-infarcted area of aged rats and human subjects}

To gain insight into the cellular function of the protein, we further performed double-immunofluorescence staining for HTR2B and Iba1, a marker of brain microglia. In the peri-infarcted area of young animals activated microglia (Figure 5A, arrowheads) was seen in close association with $\mathrm{HTR}_{2} \mathrm{~B}^{+}$neurons (Figure 5A, arrows). The close proximity of HTR2B and brain microglia was less evident at day 14 post-stroke (Figure 5B). In aged rats, however, a co-localization of the microglia marker Iba1 with HTR2B-expressing neurons and blood vessels (Bv) (Figure 5C) was seen at day 3 post stroke. Despite persistent expression of Ibal in the peri-infarcted territory (Figure 5D, inset), the co-localization between Iba1 and HtR2B was less evident by day 14 after stroke in aged animals (Figure 5D).

In the peri-lesional area of human stroke victims we noted numerous phagocytic microglia expressing AIF1 (Figure 5E, red), co-localized with HTR2B-expressing neurons (Figure 5E, green). Furthermore, numerous blood vessels were positive for HTR2B (Figure 5F, green, arrows) in remote areas with reference to the infarct core. 


\section{Chronic fluoxetine treatment stimulates post- stroke neurogenesis in aged animals}

Fluoxetine is an antidepressant of the selective serotonin reuptake inhibitor (SSRI) family that has a recognised clinical efficacy and safety profile [33]. Since the underlying mechanism may involve neurogenesis [34], we investigated the immunoreactivity of the early neuronal marker doublecortin by immunofluorescence in the lateral ventricle region of aged rats after stroke. We noted vigorous post-stroke neurogenesis as evidenced by an increased number (2.2-fold, $\mathrm{p}=0.02)$ of $\mathrm{DCX}^{+}$cells in the aged brains of animals treated with fluoxetine as compared to the modest expression in the brains of control animals (Figure 6A vs 6B) so that the number of $\mathrm{DCX}^{+}$in treated animals was almost similar to the number of $\mathrm{DCX}^{+}$ found in the subventricular zone (SVZ) of young animals ipsilateral to stroke (Figure 6C, 6D).

\section{DISCUSSION}

Despite the fact that a high proportion of elderly stroke patients develop mood symptoms, there is, as yet, little insight into the underlying neurobiological mechanisms. Following stroke, aged animals exhibit a
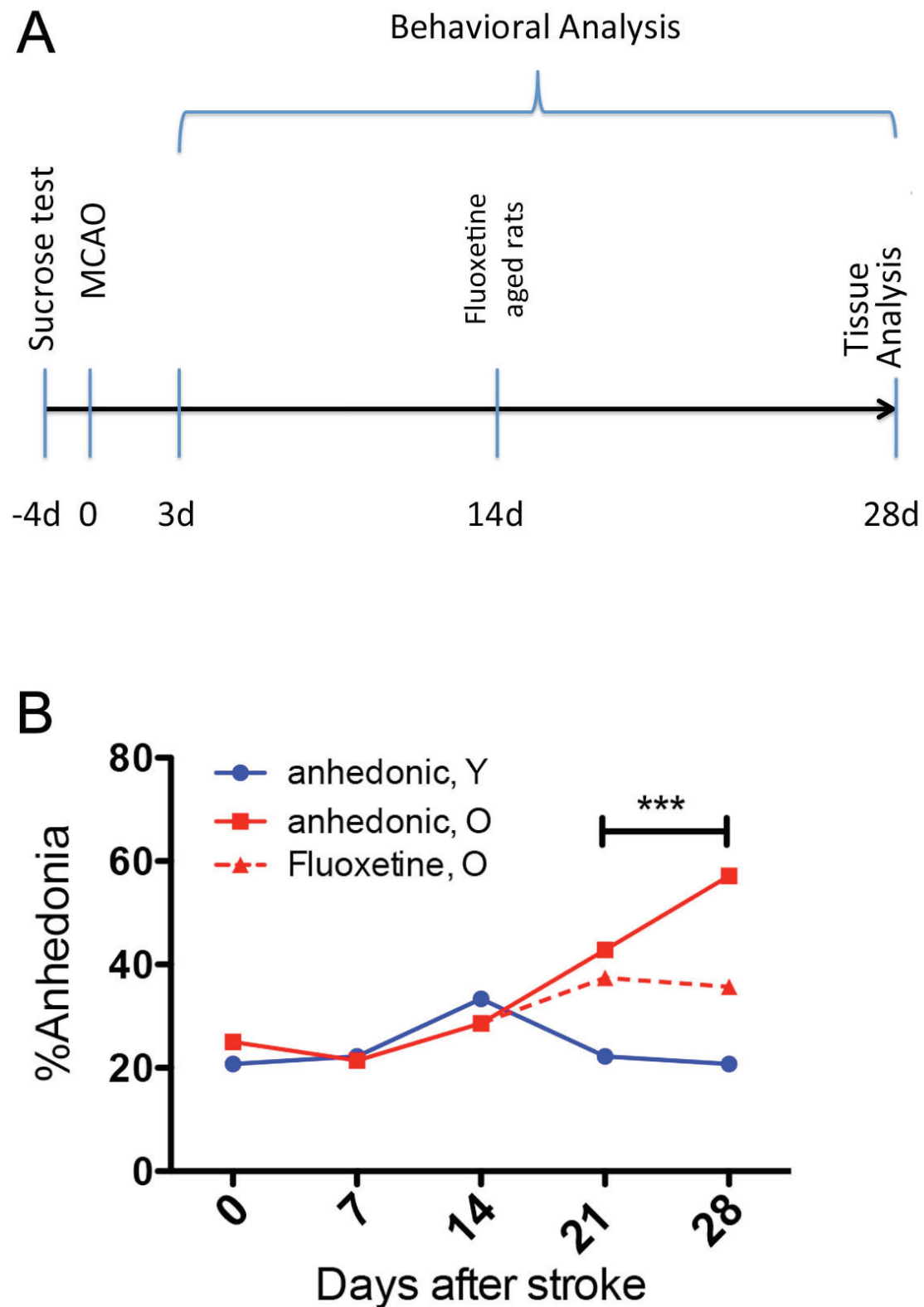

Figure 1: Experimental design and time course of spontaneous activity and hedonic behaviour after stroke.A. Schematic overview of the experimental design.B.: Before surgery, $79 \%$ of young animals (blue line) and 75\% of old animals (red line) were hedonic. After stroke, the number of anhedonic animals increased to $42 \%$ by day 21 and to $57 \%$ by day 28 . The fluoxetine treatment however did reduce anhedonic behaviour to $35 \%$ by day 28 (Figure 1B, red dashed line). $* * p<.020$. 
depressive behavior especially in the first week poststroke. We found that the expression of serotonin receptor type B mRNA was markedly increased in the peri-lesional area of aged rats as compared to the younger counterparts. Further, histologically, HTR2B protein localisation was closely associated with degenerating neurons and activated microglia both in aged rats and human subjects.

\section{Aged rats after stroke display a markedly depressive behaviour}

Following infarction, aged rats are refractory to movement and display a loss of appetite, eating and drinking a fraction of what young animals consume. Indeed, it has previously been demonstrated that aged animals lose some weight in the first week following stroke [26]. Our previous data showed that this was at least partially attributable to the surgical procedure itself during

A
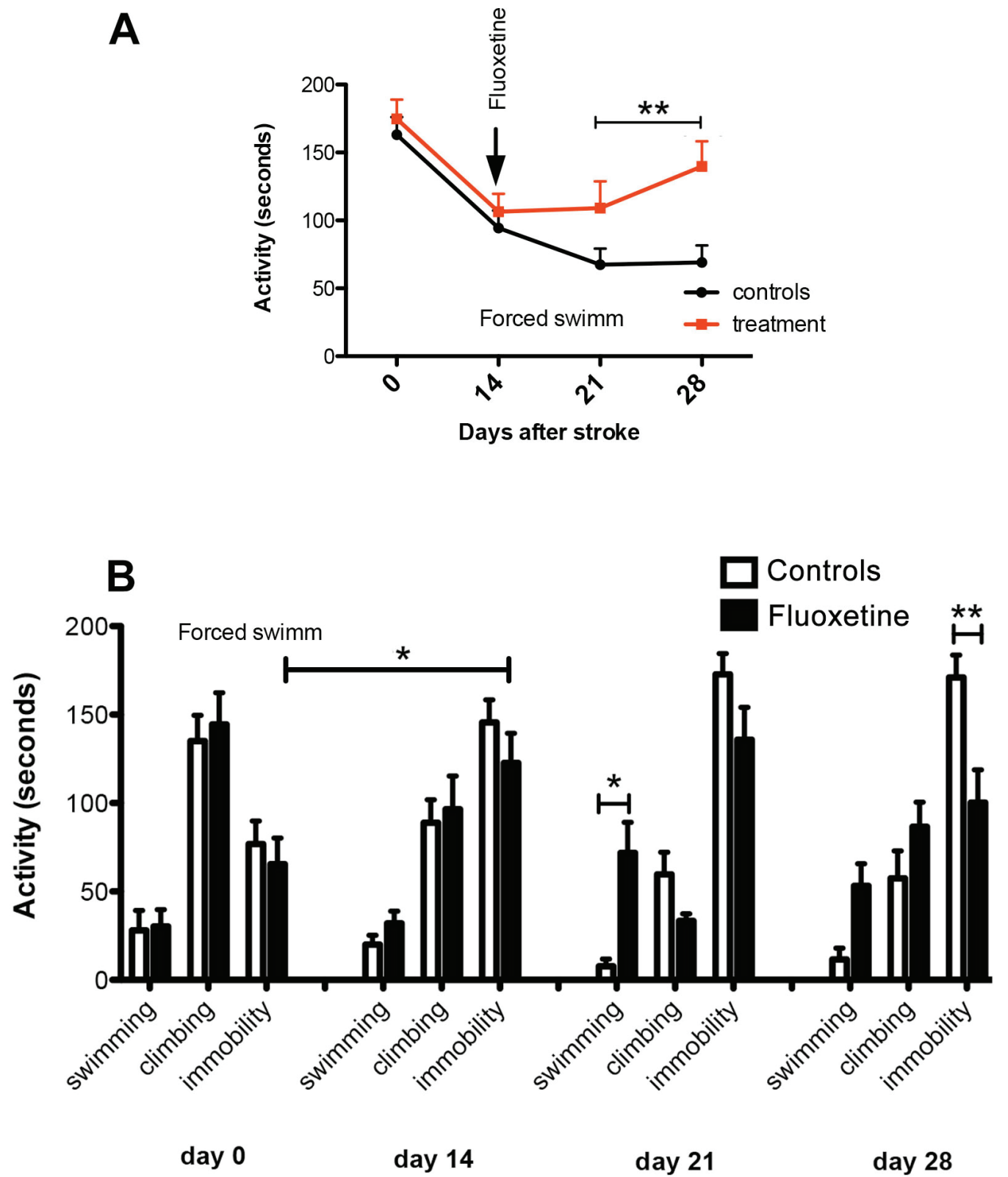

Figure 2: Assessment of post-stroke depression in aged animals. A. After stroke, forced swimm cumulative activity decreased steadily form day 1 to day 28. Fluoxetine treatment, however, reversed partially the cumulative activity (dashed line). B. By behaviour activity type, swimming had a modest contribution to the total activity index. Stroke led to an impairment of climbing activity that reached the lowest value at day 21 post-stroke while immobility increased steadily from pre-surgery levels to day 21 . The anti-depressant treatment led to an improvement in the swimming behaviour mostly ( 5 -fold increase, $p=0.001)$ followed by an improvement in immobility behaviour $(1.8$-fold, $p=0.02)$. 
the first 3 days [26, 27, 35], but thereafter it was obviously due to a depressive behaviour manifested by the lack of interest in sucrose consumption and an increase in the immobility time in the forced swim test. This depressive behaviour could be due to differentiation of serotoninergic neurons in the grey matter [36]. Generally, there is a abnormal 5-HT neurotransmission with increasing age that contributes to the deterioration of cognitive processes in ageing, including depression [37]. It is well known that young animals recover readily form stroke. In fact, aged animals exibit a delay of several days in their recovey [26]. In addition to increased cortical damage in aged animals, we believe that young animals simply have better homeostatic mechanisms allowing for behavioral recovery by functional compensation. However, as we and others previously described, this behaviour improves abruptly upon exposure to an enriched environment [26, 33, 39]. Conversely, keeping the post-stroke aged rats in isolation exacerbated the depressive behaviour [26] suggesting that depression may be at the core of decreased motility and feeding and apathic behaviour [38, 39]. Indeed, earlier studies have implicated 5-HT2BRs in anxiety, schizophrenia, autism, migraine, and depression [40, 41].

\section{Identification of an age-related increase in Htr2B mRNA after stroke}

The pattern of brain distribution suggests that the activation of 5-HT2 receptor subtypes may be implicated in the regulation of mood disorders [42]. Indeed we found that Htr2B mRNA but not Htr2A mRNA, was robustly increased in the perilesional frontal area of aged rats suggesting that the interruption in the serotoninergic innervation of cortical neurons by stroke may lead to an increased expression of Htr2B mRNA and serotonin receptors in the motor and frontal cortex.

Despite the wide occurence in the brain, the function of the 5-Htr2B receptor is not precisely known. In the brain stem, the 5-HT2B receptor modulates the respiratory network discharge properties [40] and within the vascular system, Ht2B receptors are involved in the regulation of the smooth muscle tone [43]. Moreover, because the
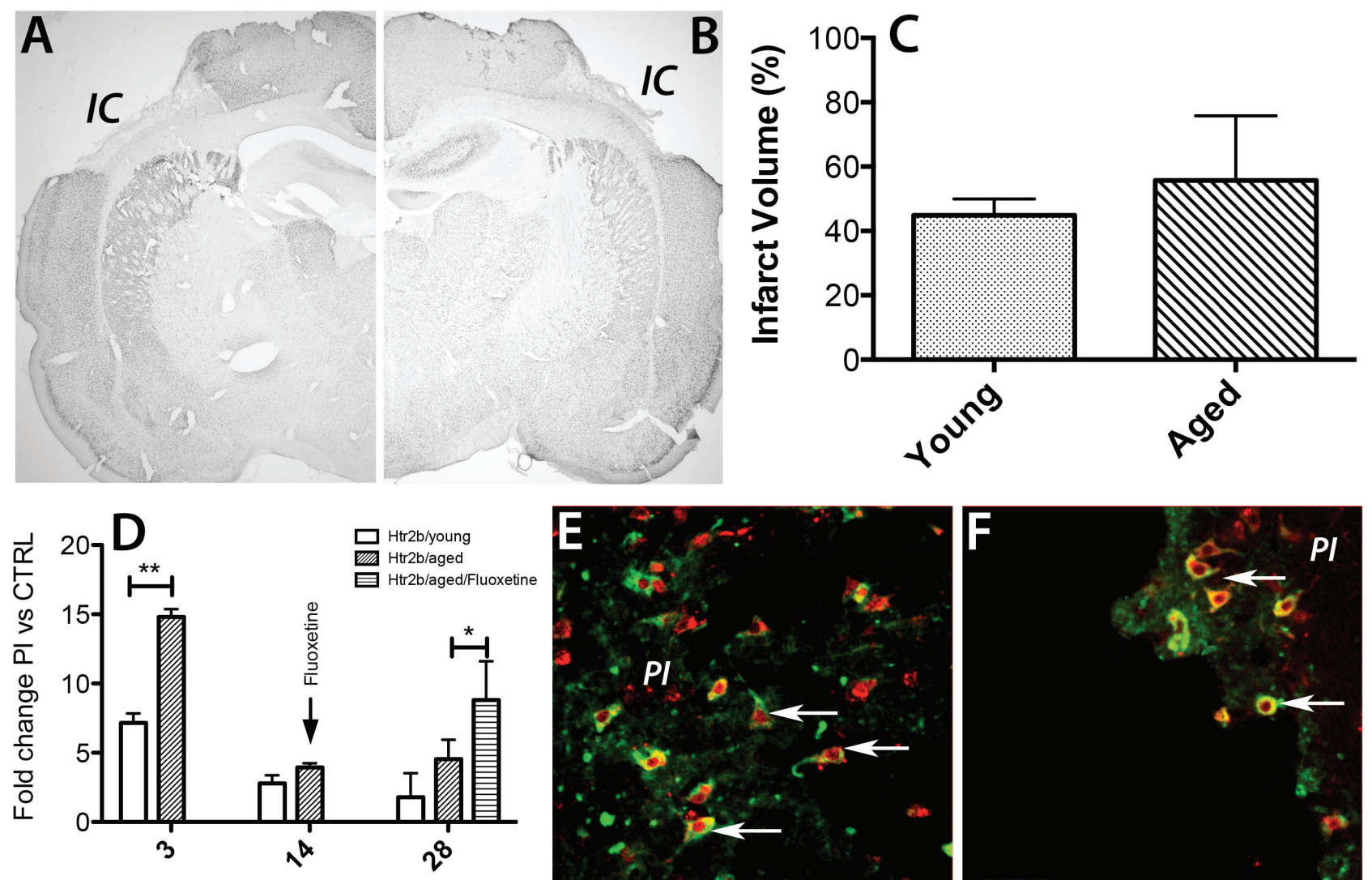

Days after stroke
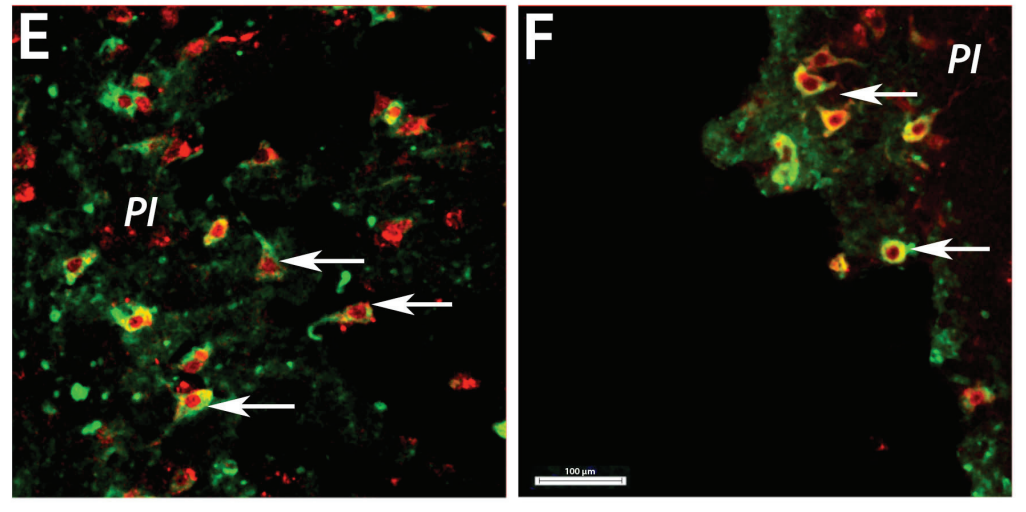

Figure 3: Age-specific post-stroke up-regulation of Htr2B mRNA in the peri-infarct area of rats. A.-C. By day 14 the cortical infarcts were similar in size in both age groups i.e. $45 \%$ of total cortical volume in young rats and $55.7 \%$ in aged rats. D. By RTPCR at day 3 post-stroke there was a 15-fold up-regulation in the expression of Htr2b mRNA that was 7-fold higher in the lesioned area of aged animals than in young animals ( $N=7$ /age group). Fluoxetine treatment, however, caused by day 28, a significant increase (1.9-fold) in the Htr2b mRNA levels in the perilesional area of aged rats E.. In the perinfarcted area of aged rats HTR2B-positive cells (green) were co-localized with NeuN-positive nuclei (red) at day3 after stroke in aged rat brains (arrows). F. Although the mRNA expression was largely down-regulated by day14 post-stroke, the HTR2B/NeuN co-localization persisted in the peri-infarcted area of aged rats (arrows). 
available ligands do not discriminate between type B and type $\mathrm{C}$ receptors, it may be that many functions attributed to the type $\mathrm{C}$ receptor could have been fulfilled by the type $\mathrm{B}$ receptor as well [44].

Among the few studies directly addressing the function of the Ht2B receptor, it was shown that the Htr2B receptor agonist alpha-methyl-5-(2-thienylmethoxy)1H-indole-3-ethanamine (BW723C86), increased food consumption and elicited anxiolysis in a social interaction model [45]. More recently, studies in Htr2B $\mathrm{KO}$ mice have shown that the $\mathrm{Ht} 2 \mathrm{~B}$ receptor is required for the hyperlocomotion induced by the "club drug" 3,4-methylenedioxymethamphetamine (MDMA; also known as ecstasy) and modulate the release of serotonin [5-hydroxytryptamine (5-HT)] stores from nerve terminals $[46,47]$.

Cognitive impairment and depression are the most commonly reported neuropsychiatric symptoms, both occurring in approximately one third of patients after stroke [48]. Apathy is most commonly defined as a syndrome of diminished goal-directed behavior, emotion, and cognition [49]. This occurs in a third of patients after stroke as an independent syndrome, although it may also occur as a symptom of depression or dementia $[50,51]$. "Apathetic" PSD, associated with bilateral basal ganglia damage, and "affective" PSD, associated to left frontal lobe lesions [52]. Moreover, a relationship between apathy and hypoperfusion of both frontal lobes after stroke has
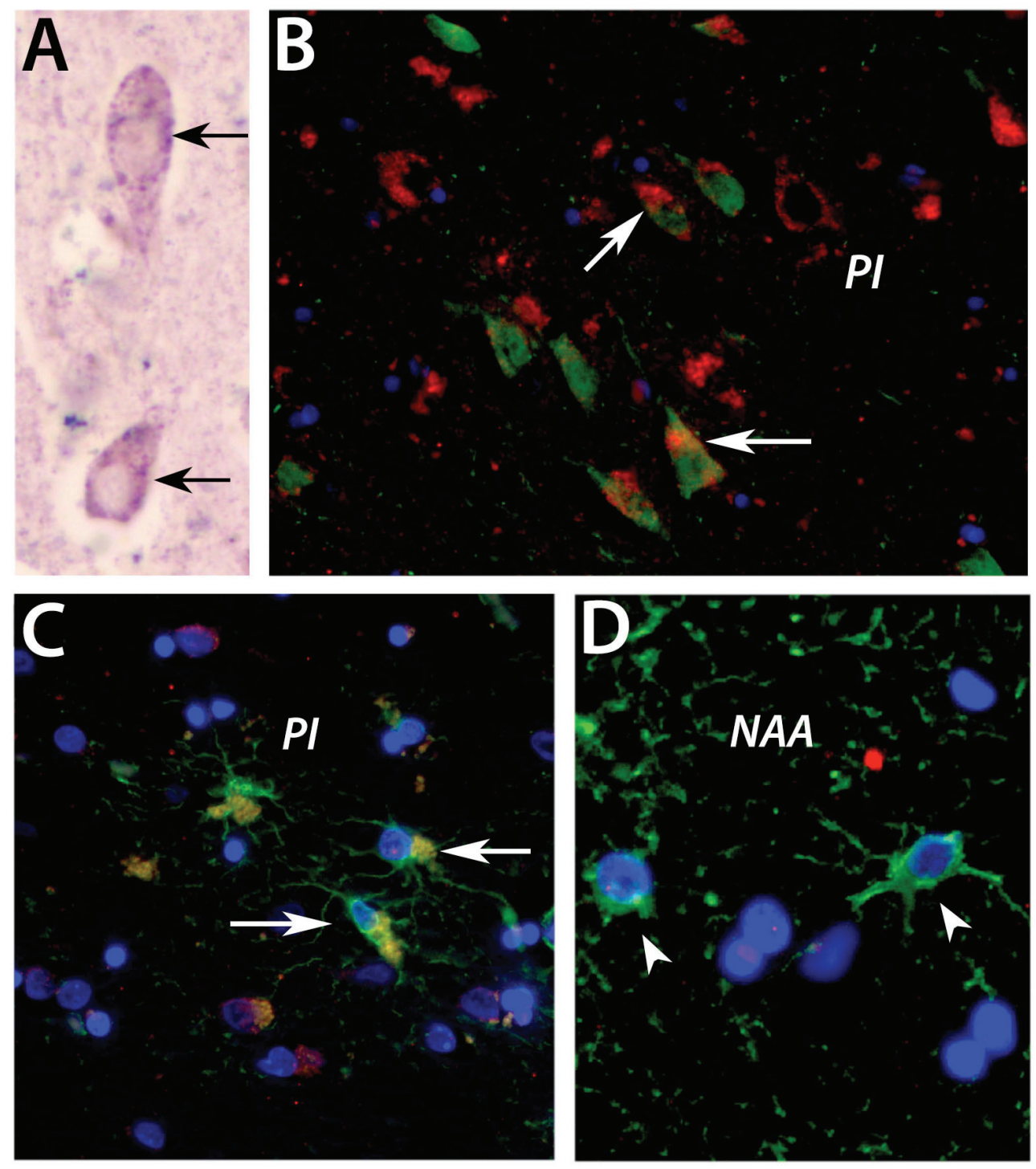

Figure 4: Histochemical localization of HTRB2B in the peri-infarct area of human subjects. By chemical immunostaining, the HTR2B receptor in human subjects has a perinuclear localization (A., arrows; Vector blue-grey development) in the penumbral region of post-mortem stroke patients. By immunofluorescence, a similar co-localization was observed in the peri-infarcted area between HTR2Bpositive cells (green) and cells labeled by beta III tubulin (red), a marker of mature neuronal cells (B., arrows). In addition to the neuronal co-localization, we also noted the co-localization with astrocytes labeled with FITC-GFAP (C., arrows) in the penumbral region of postmortem stroke patients. However, there was no co-localization with astrocytes in the unlesioned, contralateral region of the same poststroke patient (D., arrowheads).Bar, $100 \mu \mathrm{m}$. Abbreviations: PI, periinfarct. 

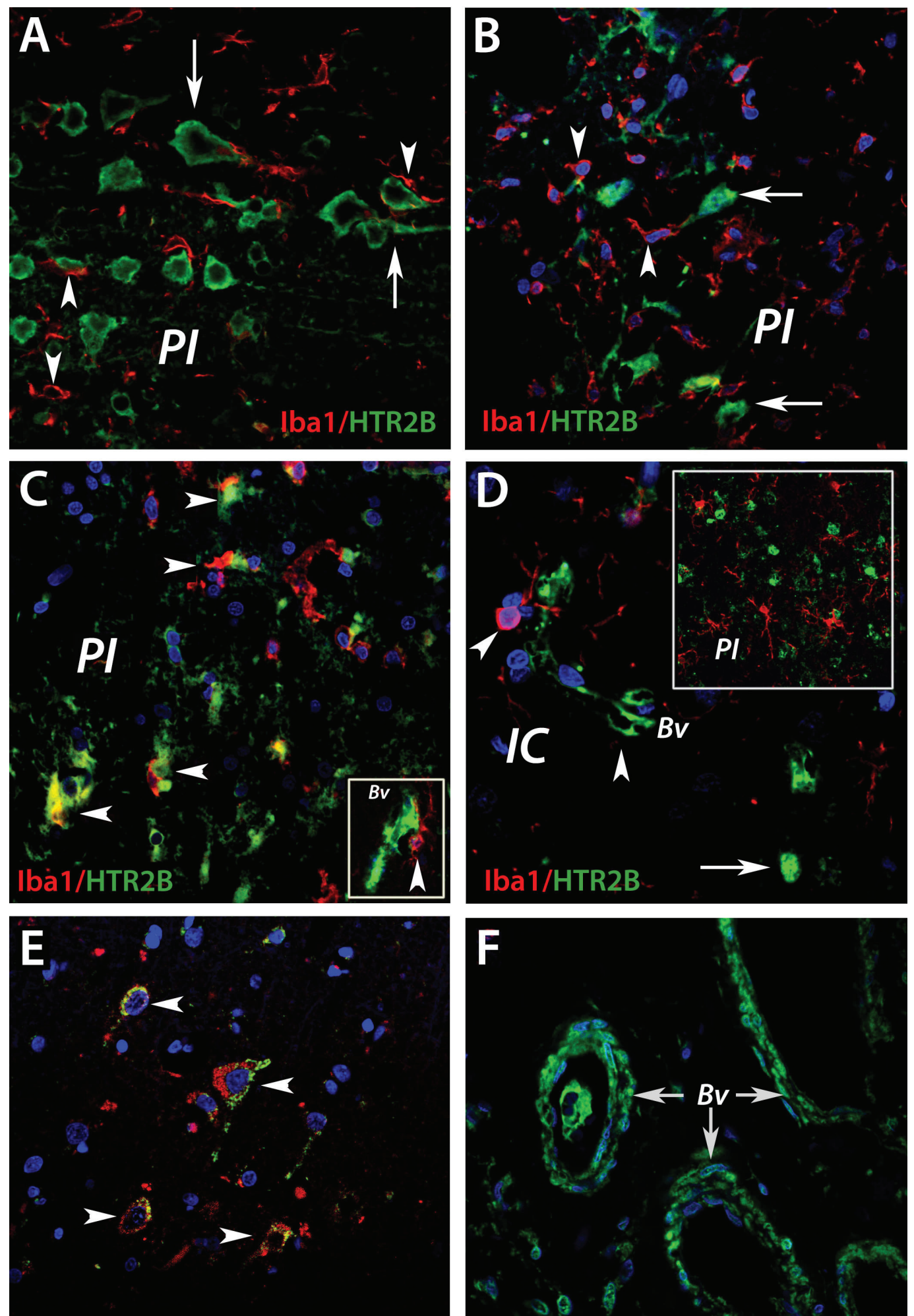

Figure 5: HTR2B is co-localized with brain macrophages in the perinfarcted area of aged rats and human subjects. A. In the peri-infarcted area of young animals, activated microglia (arrowheads) was seen in close association with $\mathrm{HTR}_{2} \mathrm{~B}^{+}$neurons (arrows). The close proximity of HTR2B and brain microglia was less evident at day 14 post-stroke B.. C. In aged rats, numerous microglial cells immunopositive for IbaI were wrapped around neurons expressing HTR2B (arrowheads), suggesting a pre-phagocytic pathology. In addition, a robust co-localization of the microglia marker Ibal with HTR2B-expressing blood vessels (inset; Bv). D. At day14, the co-localization between Ibal and HtR2B was less evident in aged animals. E. In the peri-lesional area of human stroke victims we noted numerous phagocytic microglia expressing AIF1 (red), co-localized with HTR2B-expressing neurons (green). F. In remote areas with reference to the infarct core, numerous blood vessels were positive for HTR2B (green, arrows). Bar, $100 \mu$ m. Abbreviations: Bv, blood vessel; IC, infarct core; PI, periinfarct. 
reported $[53,54]$. Since the behavior of our aged rodents was more ,apathetic“ we hypothesize that the increased HT2B mRNA and protein expression in neurons around the peri-lesional area was due to the interruption of asceding inputs from basal ganglia which normally supply neurons in the frontal cortex with biogenic amines like 5-HT and dopamine. Our hypothesis is supported by animal studies reporting an upregulation of Htr2B mRNA and protein in response to the serotonergic deafferentation to compensate for the loss of serotonin input [55] and several clinical studies in elderly patients that reported an association between old age and apathy in stroke survivors $[42,56,57]$ and normal elderly subjects [51]. Furthermore, apathy is significantly more represented in late onset depression than in early onset depression [58].

Previous studies have described that the selective serotonin reuptake inhibitors may have a beneficial effect in PSD therapy, but the role of SSRI treatment after stroke in aged animals has not been studied. Indeed, fluoxetine treatment alleviated the effect of stroke on the anhedonic
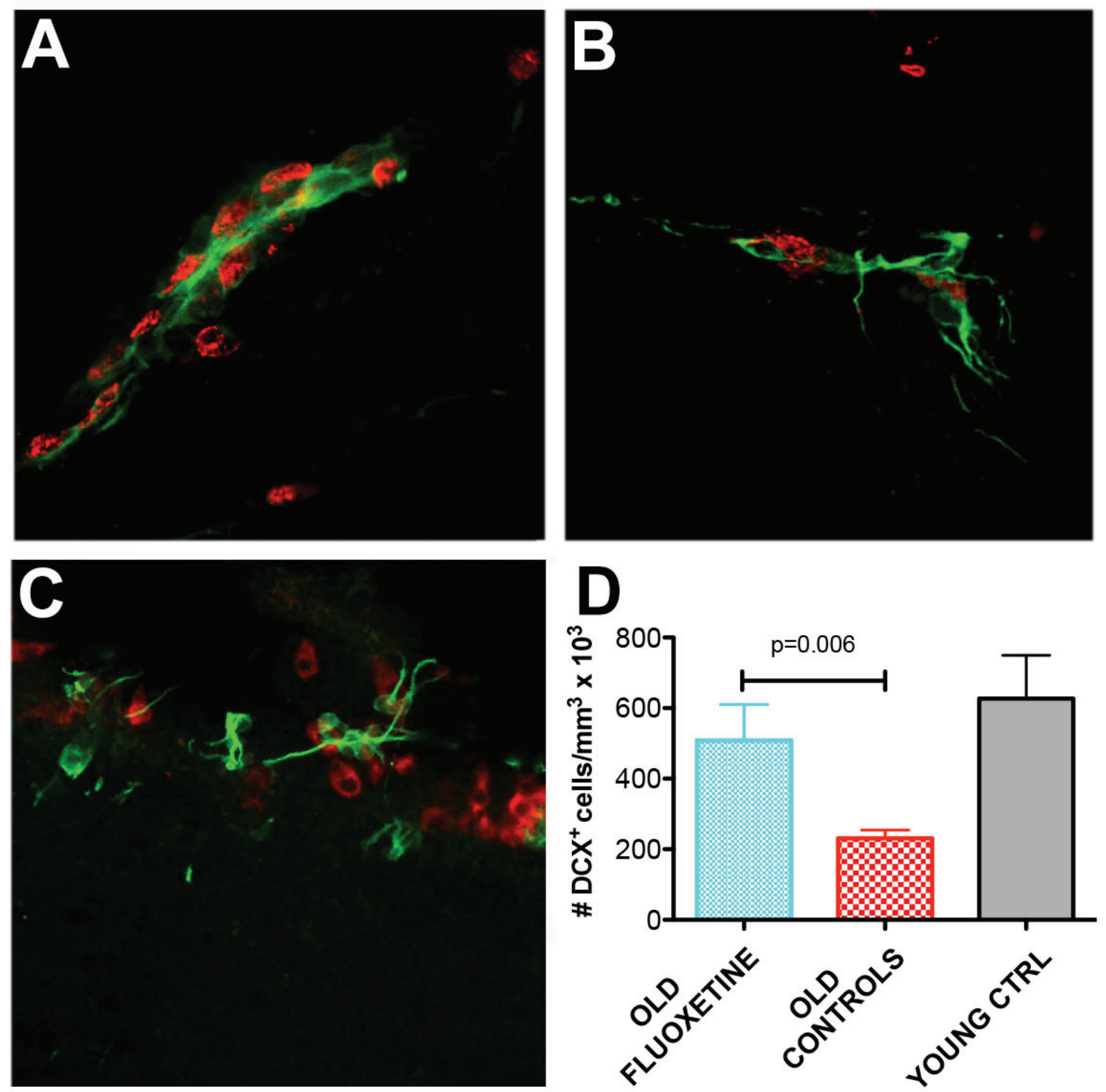

Figure 6: Fluoxetine stimulates post-stroke neurogenesis in aged animals. A.,D. Note the vigorous post-stroke neurogenesis as evidenced by an increased number of $\mathrm{DCX}^{+}$cells in the aged brains of animals treated with fluoxetine $(2.2$-fold, $p=0.02)$ as compared to the modest expression in the brains of control animals B. so that the number of $\mathrm{DCX}^{+}$in treated animals was almost similar to the number of $\mathrm{DCX}^{+}$found in the subventricular zone (SVZ) of young animals ipsilateral to stroke $\mathbf{C}$. 
behaviour indicated by an improvement in the swimming and immobility behaviour and redressed, to some extent, the expression of the Hrt2B mRNA. Our results are supported by recent suggestion that serotonin receptors are required for fluoxetine to exert its action. Thus, deletion of serotonin $1 \mathrm{~A}$ receptor from the dentate gyrus in the hippocampus abolished the anti-depressant activity of the drug [59]. In addition, we wanted to exploit the antiinflammatory effect of fluoxetine during the subacute phase in aged animals [60].

Increased cell proliferation and neurogenesis in response to chronic but not acute fluoxetine treatment may be one mechanism underlying the anti-depressant activity of fluoxetine [61]. This mechanism may also occur in the aged rats. Indeed, recent work has shown that chronic post-stroke treatment with fluoxetine increased the number of neuroblasts both in the SVZ and hippocampus of aged Wistar rats. However, since fluoxetine treatment did not influence either the survival of newly generated cells nor the performance in sensorimotor recovery [62] it is not currently known whether the newly generated neurons are functional in vivo. It has been reported that such neurons may be functionally active in hippocampal slices, a model very different from an in vivo situation [63].

Whether stroke stimulates endogenous neurogenesis is still debated especially in aged subjects where neurogenesis is normally decreased [64-68]. Recent data indicate that the action of fluoxetine on neurogenesis is highly dependent on the age of the treated individual [69]. Although several studies suggest no significant influences of fluoxetine on neurogenesis in the SVZ [61, 70] of experimental animals, it has been shown that stroke per se greatly increases neurogenesis in the subventricular zone[71]. Moreover, neurogenesis in the subventricular zone and nearby striatum after stroke is similar in young and old animals, indicating that this potential mechanism for self-repair also operates in the aged brain [72]. In addition, the beneficial effects of fluoxetine could be also due to the pleiotropic anti-inflammatory effect [60, 73]. Nevertheless, fluoxetine did stimulate post-stroke neurogenesis in the SVZ of aged animals and was associated with an improved anhedonic behavior and an increased activity in the forced swim test. However, whether endogenous neurogenesis contributes to an improved hedonic behavior has still to be established.

\section{Study limitations}

The variability of injury size and injury location following MCAO model is considerably high; (ii) extent of fluoxetine treatment beyond 14 days; (iii) since fluoxetine may also have an anti-inflammatory effect during the subacute phase in aged animals, it is not clear in what ways this effect may have impacted post-stroke neurogenesis; (iv) mechanistically, we cannot clearly distinguish between post-stroke depression and apathy.

\section{CONCLUSIONS}

Because of the lack of a precise function of the HT2B receptor in the brain, we can only speculate about the functional significance of the massive upregulation of this receptor after stroke in the aged brains. A similar upregulation of $\mathrm{HT} 2 \mathrm{~B}$ receptors has been recently reported for amyotrophic lateral sclerosis (ALS), a fatal neurodegenerative disorder affecting upper and lower motor neurons [67]. Loss of serotoninergic transmission led to a compensatory constitutive upregulation of Htr2B receptors on motor neurons causing an intrinsic hyperexcitability and subsequent spasticity [55]. A prolonged neuronal hyperexcitability may also lead to degeneration of serotoninergic neurons, and consequently attract activated microglia as we consistently observed this in the lesioned area of aged animals and autopsy samples of stroke patients. Finally, treatment with fluoxetine stimulated post-stroke neurogenesis in the SVZ and was associated with an improved anhedonic behavior and an increased activity in the forced swim test in aged animals.

\section{MATERIAL AND METHODS}

\section{Animals}

30 young (3 to 4 mo of age) and 46 aged (19 to 20 mo) male Sprague-Dawley rats, bred in-house, were used. Body weights ranged from 290 to $360 \mathrm{~g}$ for the young rats and from 520 to $600 \mathrm{~g}$ for the aged rats. After behavioural testing, the two age groups were divided randomly into 3-, 14- and 28 day post-stroke survival groups. The group sizes for the aged rats were larger to compensate for the higher post-ischemic mortality rate. After 14 days poststroke the aged group was further divided into a treatment group $(\mathrm{N}=15)$ and a control group $(\mathrm{N}=13)$. The numbers reported in the results refer to the number of animals that survived the surgery and completed the 4-week testing period. The rats were kept in standard cages in a temperature $\left(22^{\circ} \mathrm{C}\right)$, humidity $(40-60 \%)$, and light period (07.00-19.00h) controlled environment and had free access to food and water. The Animal Experimentation Institutional Animal Care and Use Committee of the University of Medicine and Pharmacy Craiova as meeting the ethical requirements of the EU legislation on the protection of animals used for experimental purposes approved all experiments.

\section{Reversible occlusion of the middle cerebral artery}

Eighteen hours prior to surgery, rats were deprived of food to minimize variability in ischemic damage that can result from varying plasma glucose levels [28]. Water remained available at all times. In all cases, craniotomy 
was performed between 9:00 and 13:00. Animals from the control and experimental groups were randomly subjected to cerebral infarction that was induced by the focal interruption of blood flow by transiently lifting the middle cerebral artery with a tungsten hook, as previously described [27]. To prevent continued perfusion of the target region by arterial collaterals, both common carotid arteries were then occluded by tightening pre-positioned thread loops. Throughout surgery, anaesthesia was maintained by spontaneous inhalation of $1-1.5 \%$ isoflurane in a mixture of $75 \%$ nitrous oxide and $25 \%$ oxygen. Body temperature was maintained at $37^{\circ} \mathrm{C}$ by a Homeothermic Blanket System (Harvard Apparatus) and the tail artery was catheterized to allow the continuous measurement of blood pressure and the withdrawal of blood samples for determination of $\mathrm{pH}$ and blood gases (Blutgassystem IL 1620, Instrumentation Laboratory, Munich), as well as arterial glucose levels (Omnican7 Balance, B. Braun, Melsungen). Local changes in blood flow were monitored using a laser Doppler device fixed in place using a tiny cylinder nearby the occluded artery (Perimed, Stockholm, Sweden), and blood gases were measured at several timepoints during ischemia. A decrease in the laser Doppler signal to $<20 \%$ of control values was considered to indicate successful MCA occlusion. After 90 minutes, the hook was released and the common carotid arteries were re-opened.

\section{Treatments}

Aged rats were given a fine suspension of fluoxetine daily, an anti-depressant drug, in saline $(10 \mathrm{mg} / \mathrm{Kg}$ body weight) administered intraperitoneally at day 14 after stroke and was continued for two weeks. The control group was treated with vehicle (saline). To label newly generated cells, all rats were treated with once-daily i.p. injections of bromodeoxyuridine (BrdU; 50mg/ $\mathrm{kg}$ body weight; Sigma, Germany) during the first week poststroke, continued at alternating days thereafter for a period of 14 days in total.

\section{Behavioural tests}

The testing procedure involved two experimenters, one who performed the surgery and was in charge of handling the animals according to group assignment, and another who carried out the behavioural tests and who was not aware of the animals' group assignments.

\section{Forced swim}

The forced swim test was used to assess the time of active/passive behavior when animals are placed in an inescapable cylinder with water (50 cm water depth) for $5 \mathrm{~min}$. Time sampling technique was used to rate the predominant behavior over a 60 -s interval. Active behavior was analyzed by three different form of active behavior: (1) climbing behavior- upward-directed movements of the forepaws along the side of the swim chamber; (2) swimming behavior; and (3) immobility, determined as absence of any directed movements of animals' head and body was scored during the first $2 \mathrm{~min}$ of the test [29].

\section{Hedonic behavior}

Sucrose consumption during a period of 24 hours was used as a measure of hedonic behavior as described in detail previously [30]. Briefly, 4 days before surgery rats were given, for $24 \mathrm{~h}$, a free choice between two bottles, one filled with $2 \%$ sucrose solution, the other containing tap water. After a break of two days, the rats were primed again with $2 \%$ sucrose for $24 \mathrm{hrs}$. To control for potential effects of side preference, the position of the bottles was switched after $12 \mathrm{~h}$. In order to balance the air temperature between the room and the drinking bottles, they were kept in the same room where the testing took place. In order to decrease stroke variability due to sucrose consumption, one day before surgery rats were given tap water. After the MCAO was performed, spontaneous activity and hedonic behaviour (sucrose and water levels) were monitored every seventh day and recorded for 4 weeks (Figure 1A). Throughout the experiment the two bottles (water and sucrose) were switched once per day, to prevent possible effects of side preference in drinking behavior. Consumption of liquids was evaluated by weighing the bottles before and after the test. Sucrose intake was given as the amount of consumed sucrose in mg per gram body weight [30].

\section{Tissue, RNA and protein analysis}

Subsequent to a survival time of 3-, 14- and 28 days, the rats were deeply anesthetized and perfused with buffered saline followed by buffered, 4\% freshly depolymerized paraformaldehyde. The brain was removed, post-fixed in buffered 4\% paraformaldehyde for $24 \mathrm{~h}$, cryoprotected in $20 \%$ sucrose prepared in $10 \mathrm{mmol} / \mathrm{L}$ phosphate-buffered saline, flash-frozen in isopentane and stored at $-70^{\circ} \mathrm{C}$ until sectioning. For total RNA and protein isolation, the rats $(\mathrm{N}=7)$ were perfused with buffered saline only, and the brain was cut into $2 \mathrm{~mm}$ slices that were dipped in 2\% 2,3,5-triphenyltetrozolium chloride (TTC) solution so that the infarct core could be visualized and microdissected under a dissecting microscope as previously described [25]. 


\section{Real Time Quantitative PCR}

Total RNA was isolated using TRIzol reagent (Invitrogen Life Technologies, Germany), as described by the manufacturer, followed by DNase 1 (Ambion) digestion and further purification using the RNeasy Mini extraction kit (Qiagen, Hilden, Germany). Purified total RNA was used for cDNA array assay and real-time PCR quantification.

For real-time PCR, $2 \mu \mathrm{g}$ of total RNA was reversetranscribed using random hexamers and the reverse transcription reagents supplied by Life Technologies (Karlsruhe, Germany). The PCR reaction was set up by mixing 10ng of cDNA, primers, and Master mix (PeqLab, Germany), and real-time PCR amplification was performed as follows: one cycle of $15 \mathrm{~min}$ at $95^{\circ} \mathrm{C}$ and 45 cycles in three steps each $\left(95^{\circ} \mathrm{C}\right.$ for $30-\mathrm{s}, 58^{\circ} \mathrm{C}$ for $30-\mathrm{s}$, $72^{\circ} \mathrm{C}$ for 30 -s) using a real-time PCR cycler (MyiQ Cycler Bio-Rad). A standard curve was generated by plotting the $\log _{10}$ [target dilution] of template on the $\mathrm{X}$-axis against the $\mathrm{Ct}$ value from serial dilutions of target DNA on the Y-axis. The efficiency of PCR amplification was $98 \%$. The relative expression level of Htr $2 B$ and Rpll3a (as the housekeeping gene) was determined based on the standard curve equation generated for each individual gene.

\section{Immunohistochemistry}

Sections (25 $\mu \mathrm{m}$-thick) were cut on a freezing microtome and processed for immunohistochemistry as free-floating material using an automatic staining device (www.tingomat.com) capable of staining several hundreds of sections simultaneously. Briefly, after incubation with blocking solutions containing $3 \%$ donkey serum $/ 10$ $\mathrm{mmol} / \mathrm{L}$ PBS $/ 0.3 \%$ Tween 20 , tissue sections were exposed overnight at $4{ }^{\circ} \mathrm{C}$ to mouse anti-NeuN (1:1000, Millipore, Germany) diluted in PBS containing 3\% normal donkey serum and $0.3 \%$ Tween 20 . After extensive washing in PBS containing $0.3 \%$ Tween, sections were incubated overnight at $4{ }^{\circ} \mathrm{C}$ with biotinylated donkey anti-mouse IgG (Jackson ImmunoResearch Laboratories, West Grove, PA) diluted 1:4000 in PBS containing 1\% normal donkey serum and $0.3 \%$ Tween 20 . After washing in PBS, sections were incubated for $4 \mathrm{hrs}$ at room temperature in $\mathrm{ABC}$ Elite reagent (Vectastain Elite Kit, Vector) diluted 1:100 in PBS containing $0.3 \%$ Tween 20 . The antibody complex was then visualized with $0.025 \% 3^{\prime}, 3^{\prime}$ 'diaminobenzidine (DAB) and $0.005 \%$ hydrogen peroxide in $100 \mathrm{mmol} / \mathrm{L}$ Tris buffer ( $\mathrm{pH} 7.5)$.

\section{Determination of infarct volume}

To assess the size of the infarct induced by transient focal ischemia, every tenth section was stained $\mathrm{NeuN}$ as previously described [31]. Briefly, images of the stained sections were taken to cover the entire infarcted area, which was then calculated as the sum of partial areas using Image J. Integration of the resulting partial volumes gave the total volume of the ipsilateral hemisphere along with the total volume of the cortical infarct; lesion volume was then expressed as percent of the hemispheric volume.

\section{Doublecortin-BrdU double staining}

Cryostat, free-floating sections of $25 \mu \mathrm{m}$ were fixed in $4 \%$ paraformaldehyde for 15 minutes and then washed extensively with PBS After incubation in 50\% Formamide/2X SSC for $2 \mathrm{~h}$ at $60^{\circ} \mathrm{C}$, sections were washed again, first in 2x SSC and then in 10x PBS. After denaturation in $2 \mathrm{~N} \mathrm{HCL}$ at $37^{\circ} \mathrm{C}$ for 40 minutes, sections were made neutral by adding $0.1 \mathrm{M}$ Borate buffer $(\mathrm{pH}$ $8,5)$. Thereafter sections were incubated sequentially with the guinea pig anti-doublecortin (1:2000; Millipore, Germany) antibody overnight at $4{ }^{\circ} \mathrm{C}$ followed by donkey anti-guinea pig IgG-biotin (Dianova, Hamburg, Germany) and streptavidin Alexa 488 (Life Technologies, Karslruhe, Germany). Finally sections were incubated with rat anti-BrdU antibody (1:2000, AbD Serotec, Puchheim, Germany). BrdU-positive cells were visualized by incubating with Cy3-conjugated donkey anti-rat IgG $(\mathrm{H}+\mathrm{L})$ (1:3000, Dianova, Hamburg, Germany).

\section{Immunofluorescence on rat brain sections}

Sections (25 $\mu \mathrm{m}$-thick) were cut on a freezing microtome and processed for immunohistochemistry as free-floating material using an automatic staining device (www.tingomat.com). For phenotyping, rat sections were blocked and incubated overnight at $4^{\circ} \mathrm{C}$ either with rabbit anti-NeuN (1:1000, Millipore, Germany) or anti-GFAP (1:1000, Abcam) or rabbit anti Ibal (1:3000, WAKO Chemie, Germany) diluted in 3\% goat serum, 1x PBS and $0,2 \%$ Tween. After overnight incubation at $4{ }^{\circ} \mathrm{C}$, sections were washed and incubated with the secondary antibody, goat anti-rabbit-CFL 555 (1:1000 dilution, Santa Cruz, Heidelberg, Germany). After a short fixation in 4\% paraformaldehyde, serotonin receptor 2B-expressing cells were visualized by incubating sequentially with mouse anti-HTR2B (1:2000, Pharmingen) followed by goat anti-mouse HRP polymer ( $1: 10$ in $1 \%$ goat serum; Histofine, Nichirei Technology). Finally, cells were stained using tyramide-FITC. Then sections were mounted in ProLong ${ }^{\circledR}$ Gold Antifade reagent with Hoechst 33342 (Life Technologies, Karlsruhe, Germany) to stain nuclei. 


\section{Immunofluorescence on human brain sections}

To analyze HTR2B expression after ischemic stroke, formalin-fixed, paraffin-embedded archived brain tissue blocks containing both cortical lesional and peri-lesional areas were selected from 12 stroke patients with a survival post-stroke time ranging from $12 \mathrm{~h}$ to 7 days. Death was attributed to complications such as massive edema and brain herniation with rostrocaudal deterioration, or cardiovascular arrhythmias. Written informed consent to autopsy was obtained for each patient from the relatives or their caregivers. Demographic data of patients and controls are given in Table 1.

$7 \mu \mathrm{m}$ sections were cut and mounted on positively charged slides (Superfrost ${ }^{\circledR}$ ), then dewaxed and rehydrated. Antigen retrieval was performed in heated $1 \mathrm{mM}$ citric acid $(\mathrm{pH} 6)$ and non-specific antigen binding was blocked in $10 \%$ goat serum in PBS. Sections were exposed to anti-5-HT2BR antibody (1:50, BD Bioscience) and either anti-AIF1 antibody (1:100, Abcam) or anti-beta III Tubulin antibody (1:1000, Abcam) diluted in 1\% goat serum in PBS, then detected using Alexa Fluor 488 and 594 secondary antibodies (Life Technologies). Sections were mounted in ProLong ${ }^{\circledR}$ Gold Antifade reagent with DAPI (Life Technologies) and visualized on a Leica DM6000 fluorescent microscope.

\section{Microscopy}

Confocal microscopy images were acquired using a Zeiss LSM710 laser-scanning confocal system with spectral detection capabilities, and Zen 2010 software version 6.0 (Carl Zeiss Microscopy GmbH, Jena, Germany) was used for image acquisition and analysis. Excitation light was provided by 488, 543, and $634 \mathrm{~nm}$ laser lines; fluorescence emission was detected at 500-530 $\mathrm{nm}$ for FITC (green), 550-600 nm for CFL 555 (red) and $360-486 \mathrm{~nm}$ for Hoechst (blue) in separate tracks, using a confocal aperture of 1 Airy unit. Some of the images were acquired as z-stacks and $3 \mathrm{D}$ reconstruction was performed.

\section{Cell Quantitation}

A quantitative estimate of the number of DCX- and BrdU-immunopositive cells was obtained by counting the cells in $25-\mu \mathrm{m}$-thick sections in volume units measuring $250 \mu \mathrm{m} \times 250 \mu \mathrm{m} \times 10 \mu \mathrm{m}$, employing a 'randomsystematic' protocol (random start point for a systematic series of every 10th section through the infarcted volume) as previously described [5]. The area occupied by cells of interest was $30 \%$ of the total stained area. The relative mean number of co-localized cells was then calculated per group, time point, and age by multiplying the number of cells per section times 3.3 (the counting boxes that were quantitated covered one third of the area of each section) times the section interval of 10 . Because co-localization in one confocal plane sometimes may be misleading as to the number of cells co-localizing, we counted doublelabeled cells by 3-D reconstruction as described above. By rotating the 3-D image, we were able to determine precisely the number of co-localized cells [5].

\section{Statistical analysis}

The age-dependency of anhedonia and the effect of treatment on the hedonic behavior were analyzed using the Mann Whitney test. The main effect of treatment on sucrose and total liquid consumption, forced swim, including swimming, climbing and immobility, was evaluated by using two-way ANOVA. Cell quantification was performed using the t-test. The level of significance (two-tailed threshold) was set at $\mathrm{p} \leq 0.05$. Data are presented as mean $\pm \mathrm{SD}$ for all other data, as indicated for each figure.

\section{ACKNOWLEDGMENTS}

This study was partially supported by a grant from the Ministry of Research and Education of Germany (UEFISCDI, PN-II-ID-PCE-2011-3-0848, «Age-related deterioration of genetic and biological pathways and their significance for brain tissue regeneration and functional recuperation after injuries" to APW.

\section{CONFLICTS OF INTEREST}

We have no conflict of interest to declare.

\section{REFERENCES}

1. Mozaffarian D, Benjamin EJ, Go AS, Arnett DK, Blaha MJ, Cushman M, de Ferranti S, Després JP, Fullerton HJ, Howard VJ, Huffman MD, Judd SE, Kissela BM et al. Heart disease and stroke statistics-2015 update: a report from the AmericanHeart Association. Circulation. 2015;131:e29-e322.

2. Ay H, Koroshetz WJ, Vangel M, Benner T, Melinosky C, Zhu M, Menezes N, Lopez CJ, and Sorensen AG. Conversion of ischemic brain tissue into infarction increases with age. Stroke. 2005; 36:2632-2636.

3. Bergerat A, Decano J, Wu CJ, Choi H, Nesvizhskii AI, Moran AM, Ruiz-Opazo N, Steffen M, and Herrera VL. Prestroke proteomic changes in cerebral microvessels in stroke-prone, transgenic [hCETP]-Hyperlipidemic, Dahl salt-sensitive hypertensive rats. Mol Med. 2001; 17:588598.

4. Gokcay F, Arsava EM, Baykaner T, Vangel M, Garg P, $\mathrm{Wu} \mathrm{O}$, Singhal AB, Furie KL, Sorensen AG, and Ay H. 
Age dependent susceptibility to infarct growth in women. Stroke. 2011; 42:947-951.

5. Popa-Wagner A, Carmichael ST, Kokaia Z, Kessler C, and Walker LC. The response of the aged brain to stroke: too much, too soon? Curr Neurovasc Res. 2007; 4:216-227.

6. Loubinoux I, Kronenberg G, Endres M, Schumann-Bard P, Freret T, and Filipkowski RK. Post-stroke depression: mechanisms, translation and therapy. J Cell Mol Med. 2012; 16:1961-1969.

7. Pompili M, Venturini P, Lamis DA, Giordano G, Serafini G, Belvederi Murri M, Amore M, Girardi P. Suicide in stroke survivors: epidemiology and prevention. Drugs Aging. 2015; 32:21-29.

8. Duman RS, and Voleti B. Signaling pathways underlying the pathophysiology and treatment of depression: novel mechanisms for rapid-acting agents. Trends Neurosci. 2012; 35:47-56.

9. Knol MJ, Twisk JW, Beekman AT, Heine RJ, Snoek FJ, and Pouwer F. Depression as a risk factor for the onset of type 2 diabetes mellitus. A meta-analysis. Diabetologia. 2006; 49:837-845.

10. Soriano-Tárraga C, Jiménez-Conde J, Giralt-Steinhauer E, Mola-Caminal M, Vivanco-Hidalgo RM, Ois A, RodríguezCampello A, Cuadrado-Godia E, Sayols-Baixeras S, Elosua R, Roquer J. Epigenome-wide association study identifies TXNIP gene associated with type 2 diabetes mellitus and sustained hyperglycemia. Hum Mol Genet. 2016; 25:609619.

11. Slevin M, Matou S, Zeinolabediny Y, Corpas R, Weston R, Liu D, Boras E, Di Napoli M, Petcu E, Sarroca S, PopaWagner A, Love S, Font MA, Potempa LA, Al-Baradie R, Sanfeliu C, Revilla S, Badimon L, Krupinski J. Monomeric C-reactive protein-a key molecule driving development of Alzheimer'sdisease associated with brain ischaemia? Sci Rep. 2015; 5:13281. doi: 10.1038/srep13281.

12. Garriga M, Milà M, Mir M, Al-Baradie R, Huertas S, Castejon C, Casas L, Badenes D, Giménez N, Font MA, Gonzalez JM, Ysamat M, Aguilar M et al. (123)I-FPCIT SPECT imaging in early diagnosis of dementia in patients with and without a vascular component. Front Syst Neurosci. 2015; 9:99. doi: 10.3389/fnsys.2015.00099.

13. Evans DL, Charney DS, Lewis L, Golden RN, Gorman JM, Krishnan KR, Nemeroff CB, Bremner JD, Carney RM, Coyne JC, Delong MR, Frasure-Smith N, Glassman AH, et al. Mood disorders in the medically ill: scientific review and recommendations. Biol Psychiatry. 2005; 58:175-189.

14. Gildengers AG, Whyte EM, Drayer RA, Soreca I, Fagiolini A, Kilbourne AM, Houck PR, Reynolds CF 3rd, Frank E, Kupfer DJ, and Mulsant BH. Medical burden in latelife bipolar and major depressive disorders. Am J Geriatr Psychiatry. 2008; 16:194-200.

15. Kessler RC, Berglund P, Demler O, Jin R, Merikangas $\mathrm{KR}$, and Walters EE. Lifetime prevalence and age-ofonset distributions of DSM-IV disorders in the National
Comorbidity Survey Replication. Arch Gen Psychiatry. 2005; 62:593-602.

16. Krishnan V, and Nestler EJ. The molecular neurobiology of depression. Nature. 2008; 455:894-902.

17. Trivedi MH, Rush AJ, Wisniewski SR, Nierenberg AA, Warden D, Ritz L, Norquist G, Howland RH, Lebowitz B, McGrath PJ, Shores-Wilson K, Biggs MM, Balasubramani GK, and Fava M. Evaluation of outcomes with citalopram for depression using measurement-based care in STAR*D: implications for clinical practice. Am J Psychiatry. 2006; 163:28-40.

18. Corominas R, Sobrido MJ, Ribasés M, Cuenca-León E, Blanco-Arias P, Narberhaus B, Roig M, Leira R, LópezGonzález J, Macaya A, and Cormand B. Association study of the serotoninergic system in migraine in the Spanish population. Am J Med Genet B Neuropsychiatr Genet. 2010; 153B:177-184.

19. Leysen JE. 5-HT2 receptors. Curr Drug Targets CNS Neurol Disord. 2004; 3:11-26.

20. Clemett DA, Punhani T, Duxon MS, Blackburn TP, and Fone KC. Immunohistochemical localisation of the 5-HT2C receptor protein in the rat CNS. Neuropharmacology 2000; 39:123-132.

21. Duxon MS, Flanigan TP, Reavley AC, Baxter GS, Blackburn TP, and Fone KC. Evidence for expression of the 5-hydroxytryptamine-2B receptor protein in the rat central nervous system. Neuroscience. 1997; 76:323-329.

22. Badan I, Buchhold B, Hamm A, Gratz M, Walker LC, Platt D, Kessler C, and Popa-Wagner A. Accelerated glial reactivity to stroke in aged rats correlates with reduced functional recovery. J Cereb Blood Flow Metab. 2003; 23:845-854.

23. Schmidt H, Zeginigg $M$, Wiltgen $M$, Freudenberger $P$, Petrovic K, Cavalieri M, Gider P, Enzinger C, Fornage M, Debette S, Rotter JI, Ikram MA, Launer LJ, and Schmidt R. CHARGE consortium Neurology working group. Genetic variants of the NOTCH3 gene in the elderly and magnetic resonance imaging correlates of age-related cerebral small vessel disease. Brain. 2011; 134:3384-3397.

24. Buga AM, Sascau M, Pisoschi C, Herndon JG, Kessler $\mathrm{C}$, and Popa-Wagner A. The genomic response of the ipsilateral and contralateral cortex to stroke in aged rats. $\mathrm{J}$ Cell Mol Med. 2008; 12: 2731-2753.

25. Buga AM, Scholz CJ, Kumar S, Herndon JG, Alexandru D, Cojocaru GR, Dandekar T, and Popa-Wagner A. Identification of new therapeutic targets by genome-wide analysis of gene expression in the ipsilateral cortex of aged rats after stroke. PLoS ONE. 2012; 7: e50985. doi:10.1371/ journal.pone.0050985.

26. Buchhold B, Mogoanta L, Suofu Y, Hamm A, Walker L, Kessler C, and Popa-Wagner A. Environmental enrichment improves functional and neuropathological indices following stroke in young and aged rats. Restorative Neurol Neurosci. 2007; 25:1-18. 
27. Popa-Wagner A, Stocker K, Balseanu A, Rogalewski A, Diederich K, Minnerup J, Margaritescu C, and Schäbitz WR. Effects of granulocyte-colony stimulating factor after stroke in aged rats. Stroke. 2010; 41:1027-1031.

28. Rehncrona S, Rosén I, and Siesjö BK. Brain lactic acidosis and ischemic cell damage: 1 . Biochemistry and neurophysiology. J Cereb Blood Flow Metab. 1981; 1:297311.

29. Cryan JF, Page ME, and Lucki I. Noradrenergic lesions differentially alter the antidepressant-like effects of reboxetine in a modified forced swim test. Eur J Pharmacol. 2002; 436:197-205.

30. Strekalova T, Spanagel R, Bartsch D, Henn FA, and Gass P. Stress-induced anhedonia in mice is associated with deficits in forced swimming and exploration. Neuropsychopharmacology. 2004; 29:2007-2017.

31. Popa-Wagner A, Badan I, Walker L, Groppa S, Patrana $\mathrm{N}$, and Kessler C. Accelerated infarct development, cytogenesis and apoptosis following transient cerebral ischemia in aged rats. Acta Neuropathol. 2007; 113:277293.

32. Popa-Wagner A, Schroder E, Walker LC, and Kessler C. beta-Amyloid precursor protein and ss-amyloid peptide immunoreactivityin the rat brain after middle cerebral arteryocclusion: effect of age. Stroke. 1998; 29:2196-2202.

33. Perez-Caballero L, Torres-Sanchez S, Bravo L, Mico JA, and Berrocoso E. Fluoxetine: a case history of its discovery and preclinical development. Expert Opin Drug Discov. 2014; 9:567-578.

34. David DJ, Samuels BA, Rainer Q, Wang JW, Marsteller D, Mendez I, Drew M, Craig DA, Guiard BP, Guilloux JP, Artymyshyn RP, Gardier AM, Gerald C, et al. Neurogenesis-dependent and -independent effects of fluoxetine in an animal model of anxiety/depression. Neuron. 2009; 62:479-493.

35. Joseph C, Buga AM, Vintilescu R, Balseanu AT, Moldovan M, Junker H, Walker L, Lotze M, and Popa-Wagner A. Prolonged gaseous hypothermia prevents the upregulation of phagocytosis-specific protein Annexin 1 and causes low amplitude EEG activity in the aged rat brain after cerebral ischemia. J Cereb Blood Flow Metab. 2012; 32:1632-1642.

36. Hawthorne AL, Wylie CJ, Landmesser LT, Deneris ES, and Silver J. Serotonergic neurons migrate radially through the neuroepithelium by dynamin-mediated somal translocation. J Neurosci. 2010 ;30:420-430.

37. Rodríguez JJ, Noristani HN, Verkhratsky A. The serotonergic system in ageing and Alzheimer's disease. Prog Neurobiol. 2012; 99:15-41

38. Hattori S, Hashimoto R, Miyakawa T, Yamanaka H, Maeno H, Wada K, and Kunugi H. Enriched environments influence depression-related behavior in adult mice and the survival of newborn cells in their hippocampi. Behav Brain Res. 2007; 180:69-76.

39. Jha S, Dong B, and Sakata K. Enriched environment treatment reverses depression-like behavior and restores reduced hippocampal neurogenesis and protein levels of brain-derived neurotrophic factor in mice lacking its expression through promoter IV. Transl Psychiatry. 2011; 1: e40. doi: 10.1038/tp.2011.33.

40. Niebert M, Vogelgesang S, Koch UR, Bischoff AM, Kron $\mathrm{M}$, Bock N, and Manzke T. Expression and function of serotonin $2 \mathrm{~A}$ and $2 \mathrm{~B}$ receptors in the mammalian respiratory network.PLoS One. 2011; 6:e21395. doi: 10.1371/journal. pone. 0021395.

41. Peng L, Gu L, Li B, and Hertz L. Fluoxetine and all other SSRIs are 5-HT2B Agonists - Importance for their Therapeutic Effects. Curr Neuropharmacol. 2014; 12:365339.

42. Quaranta D, Marra C, and Gainotti G. Post-stroke depression: Main phenomenological clusters and their relationships with clinical measures. Behav Neurol. 2012; 25:303-310.

43. Zopf DA, das Neves LA, Nikula KJ, Huang J, Senese PB, and Gralinski MR. C-122, a novel antagonist of serotonin receptor 5-HT2B, prevents monocrotaline-induced pulmonary arterial hypertension in rats. Eur J Pharmacol. 2011; 670:195-203.

44. McCreary AC, and Cunningham KA. Effects of the 5-HT2C/2B antagonist SB 206553 on hyperactivity induced by cocaine. Neuropsychopharmacology. 1999; 20:556-564.

45. Kennett GA. 5-HT drugs and eating disorders. IDrugs. 1998; 1:456-470.

46. Launay JM, Schneider B, Loric S, Da Prada M, and Kellermann O. Serotonin transport and serotonin transporter-mediated antidepressant recognition are controlled by 5-HT2B receptor signaling in serotonergic neuronal cells. FASEB J. 2006; 20:1843-1854.

47. Doly S, Valjent E, Setola V, Callebert J, Hervé D, Launay JM, and Maroteaux L. Serotonin 5-HT2B receptors are required for 3,4-methylenedioxymethamphetamine-induced hyperlocomotion and 5-HT release in vivo and in vitro. $\mathrm{J}$ Neurosci. 2008; 28:2933-2940.

48. van Dalen JW, Moll van Charante EP, Nederkoorn PJ, van Gool WA, Richard E. Poststroke apathy. Stroke. 2013; 44:851-860.

49. Robert P, Onyike CU, Leentjens AF, Dujardin K, Aalten P, Starkstein S, Verhey FR, Yessavage J, Clement JP, Drapier D, Bayle F, Benoit M, Boyer P et al. Proposed diagnostic criteria for apathy in Alzheimer's disease and other neuropsychiatric disorders. Eur Psychiatry. 2009; 24:98-104

50. Marin RS. Apathy: a neuropsychiatric syndrome. J Neuropsychiatry Clin Neurosci. 1991; 3:243-254

51. Starkstein SE, Fedoroff JP, Price TR, Leiguarda R, and Robinson RG. Apathy following cerebrovascular lesions. Stroke. 1993; 24:1625-1630

52. Hama S, Yamashita H, Shigenobu M, Watanabe A, Hiramoto K, and Kurisu K. Depression or apathy and 
functional recovery after stroke. Int J Geriatr Psychiatry. 2007; 22:1046-1051.

53. Okada K, Kobayashi S, Yamagata S, Takahashi K, and Yamaguchi S. Poststroke apathy and regional cerebral blood flow. Stroke. 1997; 28:2437-2441.

54. Andersson S, Krogstad JM, and Finset A. Apathy and depressed mood in acquired brain damage: relationship to lesion localization and psychophysiological reactivity. Psychol Med. 1999; 29:447-456.

55. Murray KC, Stephens MJ, Ballou EW, Heckman CJ, and Bennett DJ. Motoneuron excitability and muscle spasms are regulated by 5-HT2B and 5-HT2C receptor activity. J Neurophysiol. 2011; 105:731-748.

56. Brodaty H, Sachdev PS, Withall A, Altendorf A, Valenzuela MJ, and Lorentz L. Frequency and clinical, neuropsychological and neuroimaging correlates of apathy following stroke - the Sydney Stroke Study. Psychol Med. 2005; 35:1707-1716.

57. Lampe IK, Kahn RS, and Heeren TJ. Apathy, anhedonia, and psychomotor retardation in elderly psychiatric patients and healthy elderly individuals. J Geriatr Psychiatry Neurol. 2001; 14:11-16.

58. Krishnan KR, and McDonald WM. Arteriosclerotic depression. Med Hypotheses. 1995; 44:111-115.

59. Samuels BA, Anacker C, Hu A, Levinstein MR, Pickenhagen A, Tsetsenis T, Madroñal N, Donaldson ZR, Drew LJ, Dranovsky A, Gross CT, Tanaka KF, Hen R. 5-HT1A receptors on mature dentate gyrus granule cells are critical for the antidepressant response. Nat Neurosci. 2015; 18:1606-16. doi: 10.1038/nn.4116.

60. Liu D, Wang Z, Liu S, Wang F, Zhao S, Hao A. Anti-inflammatory effects of fluoxetine in lipopolysaccharide(LPS)-stimulated microglial cells. Neuropharmacology. 2011; 61:592-599.

61. Malberg JE, Eisch AJ, Nestler EJ, Duman RS. Chronic antidepressant treatment increases neurogenesis in adult rat hippocampus. J Neurosci. 2000; 20:9104-9110.

62. Sun X, Zhou Z, Liu T, Zhao M, Zhao S, Xiao T, Jolkkonen $\mathrm{J}$, and Zhao C. Fluoxetine Enhances Neurogenesis in Aged Rats with Cortical Infarcts, but this is not Reflected in a Behavioral Recovery. J Mol Neurosci. 2016; 58:233-42. doi: 10.1007/s12031-015-0662-y.

63. van Praag H, Schinder AF, Christie BR, Toni N, Palmer TD, Gage FH. Functional neurogenesis in the adult hippocampus. Nature. 2002; 415:1030-1034.
64. Hermann DM, and Chopp M. Promoting brain remodelling and plasticity for stroke recovery: therapeutic promise and potential pitfalls of clinical translation. Lancet Neurol. 2012; 11:369-380.

65. Jinno S. Decline in adult neurogenesis during aging follows a topographic pattern in the mouse hippocampus. J Comp Neurol. 2011; 519:451-466.

66. Enwere E, Shingo T, Gregg C, Fujikawa H, Ohta S, and Weiss S. Aging results in reduced epidermal growth factor receptor signaling, diminished olfactory neurogenesis, and deficits in fine olfactory discrimination. J Neurosci. 2004; 24:8354-8365.

67. Dentel C, Palamiuc L, Henriques A, Lannes B, SpreuxVaroquaux O, Gutknecht L, René F, Echaniz-Laguna A, Gonzalez de Aguilar JL, Lesch KP, Meininger V, Loeffler JP, Dupuis L. Degeneration of serotonergic neurons in amyotrophic lateral sclerosis: a link to spasticity. Brain. 2013; 136:483-493.

68. Moraga A, Pradillo JM, García-Culebras A, PalmaTortosa S, Ballesteros I, Hernández-Jiménez M, Moro MA, Lizasoain I. Aging increases microglial proliferation, delays cell migration, and decreases cortical neurogenesis after focal cerebral ischemia. J Neuroinflammation. 2015; 12:87. doi: 10.1186/s12974-015-0314-8.

69. Couillard-Despres S, Wuertinger C, Kandasamy M, Caioni M, Stadler K, Aigner R, Bogdahn U, Aigner L. Ageing abolishes the effects of fluoxetine on neurogenesis. Mol Psychiatry. 2009; 14:856-864.

70. Li WL, Cai HH, Wang B, Chen L, Zhou QG, Luo CX, Liu N, Ding XS, Zhu DY. Chronic fluoxetine treatment improves ischemia-induced spatial cognitive deficits through increasing hippocampal neurogenesis after stroke. J Neurosci Res. 2009; 87:112-122.

71. Darsalia V, Heldmann U, Lindvall O, Kokaia Z. Strokeinduced neurogenesis in aged brain. Stroke. 2005; 36:17901795.

72. Lindvall O, Kokaia Z. Neurogenesis following Stroke Affecting the Adult Brain. Cold Spring Harb Perspect Biol. 2015; 7. pii: a019034. doi:10.1101/cshperspect.a019034.

73. Arreola R, Becerril-Villanueva E, Cruz-Fuentes C, VelascoVelázquez MA, Garcés-Alvarez ME, Hurtado-Alvarado G, Quintero-Fabian S, PavónL. Immunomodulatory effects mediated by serotonin. J Immunol Res. 2015;2015:354957. doi: $10.1155 / 2015 / 354957$. 